\title{
Audit of insulin prescription patterns and associated burden among diabetics in a tertiary health institution in Nigeria
}

\author{
Michael A Olamoyegun ${ }^{1}$, Akinyemi T Akinlade², Oluwabukola A Ala ${ }^{3}$
}

\begin{abstract}
1. Department of Internal Medicine, Endocrinology, Diabetes \& Metabolism Unit, Ladoke Akintola University of Technology, \& LAUTECH Teaching Hospital, Ogbomoso, Oyo State, Nigeria.

2. Department of Medicine, General Hospital Odan, Lagos Nigeria.

3. Department of Medicine, BOWEN University \& BOWEN University Teaching Hospital, Ogbomoso.
\end{abstract}

\begin{abstract}
Background: Insulin is one of the most important anti-diabetic agents in the management of diabetes even among type 2 diabetic.

Objective: There was need to assess insulin adherence, mode of insulin delivery and burden of insulin usage among diabetics. Methods: A cross-sectional, prospective questionnaire, orally administered at a Diabetes Clinic of a University Teaching Hospital, SouthWest, Nigeria. Participants were consecutive patients with diabetes who were 18 years or older presently on insulin either alone or in combination with other anti-diabetic agents for at least 3 months. Baseline demographic and insulin treatment information were obtained.
\end{abstract}

Results: Two hundred and thirteen (213) participants were studied. Of these, 21 (9.9\%) had T1DM and 192 (90.1\%) had T2DM, (means age, $58.6 \pm 13.1$ years, mean duration of diabetes, $7.0 \pm 6.9$ years). Insulin adherence was noted in $72.8 \%$ with better adherence among those who self-injected insulin compared to those who were injected by health care professionals (HCPs) or relations. Among the respondents, $80.8 \%$ were on human insulin and pre-mixed insulin was the most commonly used form of insulin (52.6\%). Most participants (52.6\%) were taking 10-20 units per day, only $22(10.3 \%)$ were on $>40$ units/day. Reuse of insulin needle was found in $74.6 \%$ of the participants. Major reasons for insulin omission were non-availability of insulin and patients being tired of insulin injection.

Conclusion: The insulin adherence among diabetics in this study was high. Non-availability of insulin, insulin injection pain and being tired of continual insulin usage were some of the reasons for non-adherent to insulin usage.

Keywords: Adherence, diabetes, burden, insulin injection, omission.

DOI: https://dx.doi.org/10.4314/ahs.v18i4.3

Cite as: Olamoyegun MA, Akinlade AT, Ala $\mathrm{OA}$. Audit of insulin prescription patterns and associated burden among diabetics in a tertiary bealth institution in Nigeria. Afri Health Sci. 2018;18(4): 852-864. bttps:/ / dx.doi.org/10.4314/ abs.v18i4.3

\section{Corresponding author:}

Michael A Olamoyegun,

Department of Internal Medicine,

Endocrinology, Diabetes \& Metabolism Unit, Ladoke Akintola University of Technology,

\& LAUTECH Teaching Hospital, Ogbomoso,

Oyo State, Nigeria.

Tel: +2348035755239

Email: dryemi@yahoo.com

\section{Background}

The burden of diabetes mellitus (DM) and its complication is increasing worldwide and more markedly in the sub-Saharan Africa including Nigeria. Diabetes mellitus is a significant contributor to global morbidity and mortality. The most recent statistics by the International Diabetes Federation (IDF) estimate that in 2015 there were 415 million people living with DM globally ${ }^{1}$. In Nigeria, the reported prevalence of DM ranges from 4.4 to $11.0 \% 0^{2-6}$. Out of this number, between $14.2 \%$ and $20.8 \%$ of persons with type 2 diabetes are treated with insulin therapy

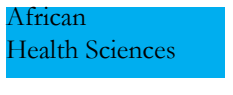

(C) 2018 Olamoyegun et al. Licensee African Health Sciences. This is an Open Access article distributed under the terms of the Creative commons Attribution License (https://creativecommons.org/licenses/BY/4.0), which permits unrestricted use, distribution, and reproduction in any medium, provided the original work is properly cited. 
either alone or in combination with oral or non-insulin anti-diabetic agents ${ }^{7-9}$. Furthermore, with recent introduction of insulin analogues into the Nigerian market and adoption of treatment-specific guideline along with the training of health care practitioners there would be a rise in the rate of insulin use among individuals with diabetes.

Insulin therapy is an integral part of diabetes management in both type 1 diabetes mellitus (T1DM) and type 2 diabetes mellitus (T2DM). In T1DM, insulin therapy is required from the time of diagnosis and continued to be required over the lifetime of an individual. In T2DM, insulin therapy is used either during acute illness associated with hyperglycaemia and hyperglycaemic emergencies, peri-operatively, or during pregnancy and lactation. Longterm insulin therapy in T2DM is indicated following the failure of combination anti-diabetic therapy with oral or non-insulin injectables to maintain optimal glycaemic control $^{10 .}$ Insulin therapy is usually initiated gradually, progressing from once daily insulin regimens to premixed, basal-plus or basal-bolus insulin regimens while the patient is maintained on certain oral anti-diabetic therapies. Two types of insulin are currently in use in Nigeria i.e. human insulin derived by recombinant technology or insulin analogues which are genetically modified human insulin in which the amino acids sequence has been altered to change the pharmacokinetic profile.

The pattern of anti-diabetic treatment (especially in type 2 diabetes mellitus) tends to change markedly along with the duration of diabetes including use of Insulin in its treatment. Studies have reported the benefits of insulin in helping to achieve glycaemic control and reduce the risk of long-term diabetes complications ${ }^{11,12}$. However, studies have shown concerns and barriers to initiation and adherence to insulin therapy especially among type 2 diabetics ${ }^{13}$. These include errors or inaccuracies associated with the injections across the lifespan of people with diabetes ${ }^{14}$. The effectiveness of insulin therapy is related to adequate dosing, adherence, preservation of its potency through proper storage and good injection techniques among others.

The objective of this study was to report the pattern of insulin use, types, prescription, storage, common regimen used, adherence, sites of insulin injection and whether insulin use interferes with daily routines among other determinants in patients with diabetes..

\section{Methodology}

This was a descriptive, cross-sectional prospective study which was carried out at the Diabetic Clinic of the LAUTECH Teaching Hospital, Ogbomoso, Oyo State. Consecutive patients diagnosed of diabetes mellitus, aged at least 18 years old, that were on insulin for at least 3 months (either alone or in combination with oral or non-insulin injectables anti-diabetic agents) and fulfilled inclusion criteria were recruited over a period of 5 months (August to December 2016). Diabetic patients aged less than 18 years old, or those older than 18 years but not on any form of insulin use or on insulin for less than 3 months or those who were acutely ill were excluded. The physicians involved in the study were specially trained for the study.

The following variables were obtained from each of the participants: age, gender, type of diabetes, duration of diabetes, and current therapy for diabetes management. Other information obtained were types of insulin treatment, dosage of insulin used/day, number of daily injection, site of injection, devices used, rotation of injection areas, frequency of needle or syringe reuse, and adherence. Nature of occupation was also obtained with monthly income for those who earned salary. Clinical examination was carried out to determine anthropometric indices, level of blood pressure and insulin injection sites.

\section{Burden of injections}

Interference with eating and exercise was measured as the mean of two items asking, "How much does the way you inject insulin interfere with eating/exercising when you want?" (Response options: $1=$ not at all, $2=$ a little, $3=\mathrm{a}$ moderate amount, $4=$ a great deal $)$. The reliability of this scale was moderate $(\alpha=0.80)$. Interference with activities of daily living was measured as a count of the affirmative responses to the question, "Do your insulin injections have a negative effect on: social activities, recreational activities, sexual activity, work/career, family care-giving?" (Possible range $=0-5$ ). Another measure of interference was whether the respondent plans daily activities around insulin injections $(1=$ yes, $0=$ no $)$. 


\section{Experience with insulin injections}

There were four measures-dissatisfaction with injection time needed, ease of use, pain and embarrassment — each measured by a single item (response options: $1=$ very satisfied, $2=$ satisfied, $3=$ somewhat satisfied, $4=$ not at all satisfied).

Frequency of intentional/forgetting to take insulin omission

The dependent variable in this study was the response to the question, "How often do you skip insulin injections that you know you should take?" (Response options: $1=$ never, $2=$ rarely, $3=$ sometimes, $4=$ often). "How often do you forget to take insulin injection you were meant to take? (Response options: 1 = never, $2=$ rarely, $3=$ sometimes, 4 = often).

\section{Definition of terms}

The subjects were considered as having diabetes mellitus if diagnosis had been previously made by their physician as diabetics and were taking anti-diabetic agents.

Type 1 diabetes was defined by clinical criteria-onset before 30 years of age and using insulin since diagnosis ${ }^{15}$.

Type 2 diabetes were classified as having type 2 diabetes mellitus using clinical criteria such as onset after 30 years of age and present/prior history of usage of oral anti-diabetic agents.
Levels of glycaemic control was determined using average of 3 most recent fasting plasma glucose (FPG) and good glycaemic control referred to $F P G \leq 126 \mathrm{mg} / \mathrm{dl}$ $(7.0 \mathrm{mmol} / \mathrm{L})$

\section{Statistical analysis}

All statistical analyses were performed with the SPSS 18.0 software package (SPSS Inc., Chicago, Illinois, USA). Numerical variables are summarized as means \pm standard deviation and categorical variables as percentage. The significance level was $\mathrm{p}<0.05$.

\section{Results}

\section{Socio-demographic characteristics}

The study included 213 participants, of which 114 $(53.5 \%)$ were females. The mean age of the participants was $58.57 \pm 13.10$ years, and at least half, $107(50.2 \%)$ of the participants were 60 years old and above. Of the participants, $21(9.9 \%)$ and $192(90.1 \%)$ had T1DM and T2DM respectively. More than sixty percent of the participants, $136(63.9 \%)$ had secondary and/or tertiary educations, and almost four-fifth, 175 (82.2\%) were married. About sixteen percent $(15.5 \%)$ of the participants were unemployed, while the rest are farmers, artisans, traders and civil servants. The mean fasting plasma glucose of the participants was $210.1 \pm 96.1 \mathrm{mg} / \mathrm{dl}$ and 111 (52.1\%) had hypertension (Table 1). 
Table 1: Socio-demographic characteristics of the participants

\begin{tabular}{|c|c|c|c|}
\hline \multirow{2}{*}{\multicolumn{2}{|c|}{ Variable }} & \multirow{2}{*}{\multicolumn{2}{|c|}{$\mathrm{N}=213$}} \\
\hline & & & \\
\hline Age Group (Years) & & Frequency & Percentage \\
\hline & $<40$ & 16 & 7.5 \\
\hline & $40-59$ & 90 & 42.3 \\
\hline & $\geq 60$ & 107 & 50.2 \\
\hline & Mean \pm SD & \multicolumn{2}{|c|}{$58.57 \pm 13.10$} \\
\hline \multirow[t]{2}{*}{ Sex } & Male & 99 & 46.5 \\
\hline & Female & 114 & 53.5 \\
\hline \multicolumn{4}{|l|}{ Religion } \\
\hline & Christianity & 149 & 70.0 \\
\hline & Islam & 63 & 29.5 \\
\hline & Traditional & 1 & 0.5 \\
\hline \multicolumn{4}{|l|}{ Education } \\
\hline & None & 23 & 10.8 \\
\hline & Primary & 60 & 28.2 \\
\hline & Secondary & 71 & 33.3 \\
\hline & Tertiary & 59 & 27.7 \\
\hline \multicolumn{4}{|l|}{ Income } \\
\hline & $<20,000$ & 99 & 46.5 \\
\hline & $20,000-50,000$ & 65 & 30.5 \\
\hline & $50,000-100,000$ & 36 & 16.9 \\
\hline & $>100,000$ & 13 & 6.1 \\
\hline \multicolumn{4}{|l|}{ Occupation } \\
\hline & Unemployed & 33 & 15.5 \\
\hline & Farming & 16 & 7.5 \\
\hline & Trading & 54 & 25.4 \\
\hline & Artisan & 12 & 5.6 \\
\hline & Civil Servant & 37 & 17.4 \\
\hline & Professional Job & 3 & 1.4 \\
\hline & Others & 58 & 27.2 \\
\hline \multicolumn{4}{|l|}{ Diabetes type } \\
\hline & Type 1 & 21 & 9.9 \\
\hline & Type 2 & 192 & 90.1 \\
\hline \multicolumn{4}{|l|}{ History of Hypertension } \\
\hline & Yes & 111 & 52.1 \\
\hline & No & 102 & 47.9 \\
\hline \multicolumn{4}{|l|}{ History of smoking } \\
\hline & Yes & 8 & 3.8 \\
\hline & No & 205 & 96.2 \\
\hline \multicolumn{4}{|l|}{ History of Alcohol } \\
\hline & Yes & 16 & 7.5 \\
\hline & No & 197 & 92.5 \\
\hline \multirow{3}{*}{$\begin{array}{l}\text { Good glycaemic control (FPG } \\
<126 \mathrm{mg} / \mathrm{dl})\end{array}$} & & & \\
\hline & Yes & 69 & 32.4 \\
\hline & No & 144 & 67.6 \\
\hline \multirow[t]{2}{*}{ Duration of Diabetes (years) } & Mean \pm SD & \multicolumn{2}{|c|}{$7.04 \pm 6.94$} \\
\hline & Median (Range) & \multicolumn{2}{|c|}{$5.00(0.10-54.0)$} \\
\hline Duration of Insulin (years) & Median (Range) & \multicolumn{2}{|c|}{$1.50(0.10-40.0)$} \\
\hline FPG (mg/dl) & Mean \pm SD & \multicolumn{2}{|c|}{$210.09 \pm 96.14$} \\
\hline
\end{tabular}

${ }^{*} F P G=$ fasting plasma glucose, $S D=$ standard deviation

\section{Patterns of insulin used}

The number of insulin injected per day was one in 39 $(18.3 \%)$, two in $159(74.6 \%)$, three in $13(6.1 \%)$ and more than three in $2(0.8 \%)$. Insulin administration devices used were insulin syringes $118\left(55.4^{\circ}\right.$ ) and insulin pen 95 (44.6\%). Majority of participants, 153 (71.8\%) self-inject themselves, while spouses, relatives and health care providers assists others with insulin injection (Table 2). 
Table 2: Insulin pattern

\begin{tabular}{|c|c|c|c|}
\hline \multirow{2}{*}{\multicolumn{2}{|c|}{ Variable }} & \multicolumn{2}{|c|}{$\mathrm{N}=213$} \\
\hline & & Frequency & Percentage \\
\hline \multirow[t]{8}{*}{ Insulin Type } & & & \\
\hline & Rapid acting & 28 & 13.1 \\
\hline & Soluble & 47 & 22.1 \\
\hline & NPH & 9 & 4.2 \\
\hline & Premixed & 112 & 52.6 \\
\hline & Long-acting & 13 & 6.1 \\
\hline & Soluble + NPH & 3 & 1.4 \\
\hline & Soluble + NPH + Premixed & 1 & 0.5 \\
\hline \multicolumn{4}{|l|}{ Insulin Frequency } \\
\hline & Once & 39 & 18.3 \\
\hline & Twice & 159 & 74.6 \\
\hline & Thrice & 13 & 6.1 \\
\hline & $>3$ times & 2 & 0.9 \\
\hline \multicolumn{4}{|l|}{ Device Type } \\
\hline & Syringes & 118 & 55.4 \\
\hline & Pen & 95 & 44.6 \\
\hline \multicolumn{4}{|l|}{ Insulin Amount } \\
\hline & $<10 \mathrm{U}$ & 15 & 7.0 \\
\hline & $10-20 \mathrm{U}$ & 112 & 52.6 \\
\hline & $21-40 \mathrm{U}$ & 64 & 30.0 \\
\hline & $>40 \mathrm{U}$ & 22 & 10.3 \\
\hline \multicolumn{4}{|l|}{ Location Insulin is kept } \\
\hline & Refrigerator & 179 & 84.0 \\
\hline & Beside clay water pot & 3 & 1.4 \\
\hline & Inside cup of water & 7 & 3.3 \\
\hline & Under the bed & 4 & 1.9 \\
\hline & Others & 20 & 9.4 \\
\hline
\end{tabular}

${ }^{*} \mathrm{NPH}=$ Neutral Protamine Hagedon

\section{Insulin injection technique $\boldsymbol{\&}$ insulin storage}

In this study, the most commonly used site for injection was thigh only in $75(35.2 \%)$, then only arm 39 (18.3\%) and least in buttock $6(2.8 \%)$,and many participants used more than one site for injection (Figure 1A). However, significantly higher number of participants was rotating the injection site with each injection. A large proportion $(43.1 \%)$ of patients reused the same needle for injecting for more than 3 times, and some $(15.0 \%)$ reused needle for up to 10 times before discarding. 


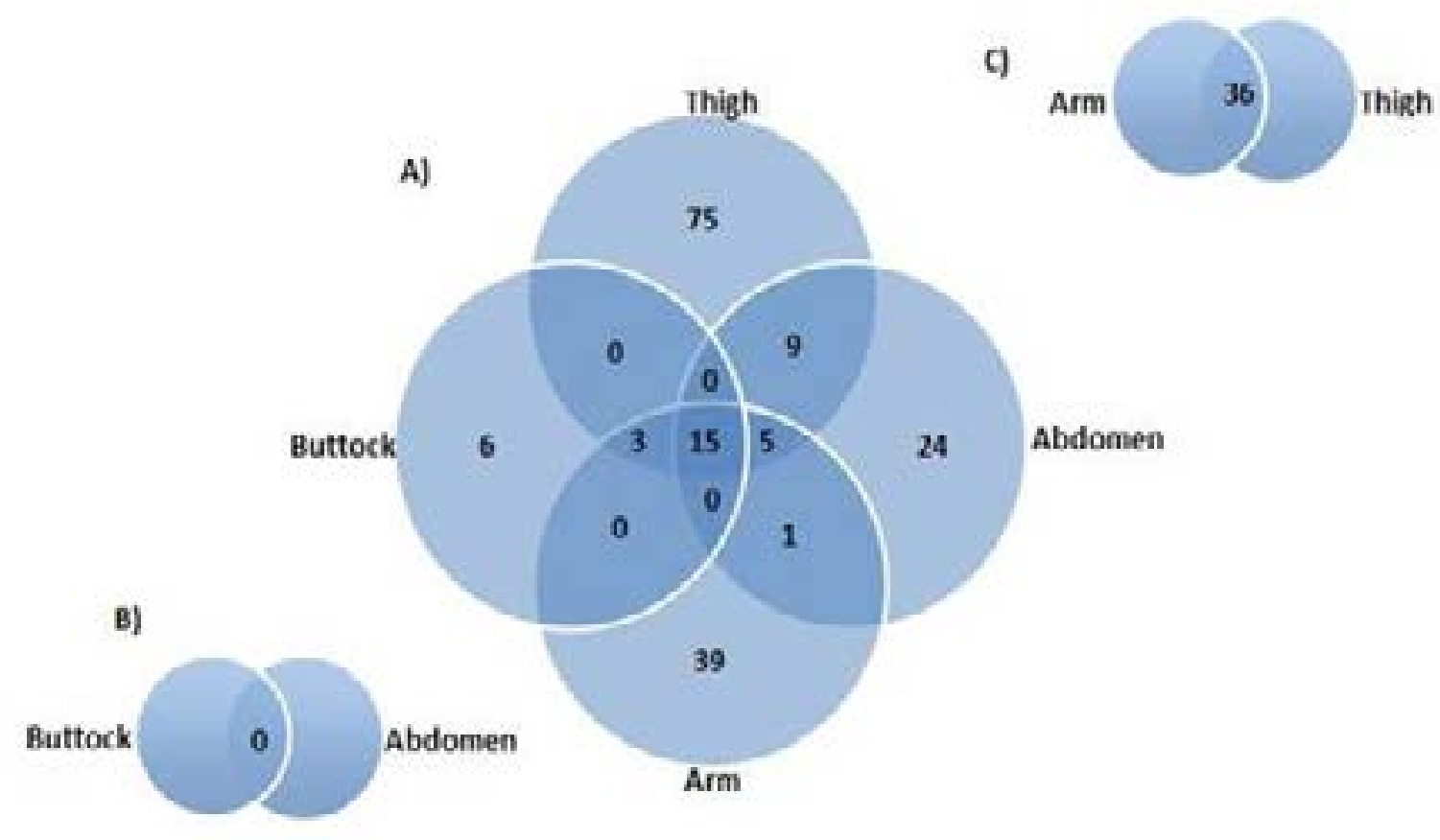

Figure 1.A. Venn diagram showing the frequencies of and overlap between different sites of insulin injection in the patients. B. Representation of abdomen and buttock. C. Representation of arm and thigh.

\section{Insulin adherence}

Adherence to insulin administration was noted in $72.8 \%$ of the study participants. Short time glycaemic control i.e. FPG $\leq 126 \mathrm{mg} / \mathrm{d}$; $(7.0 \mathrm{mmo} / \mathrm{L})$ was achieved in $69(32.4 \%)$. The mean FPG was significantly higher $(p=0.03)$ in those who admitted to non-insulin adherence compared to those who adhered to their insulin regimens. More than a quarter $(27.2 \%)$ of participants reported skipping insulin injections they should take; out of which $14.6 \%$ of these reported skipping insulin sometimes or often. A greater proportion of persons who self-injected insulin adhered to insulin prescription compared to those whose injections are administered by others (Table 3 ). 
Table 3: Insulin Injection techniques and practices

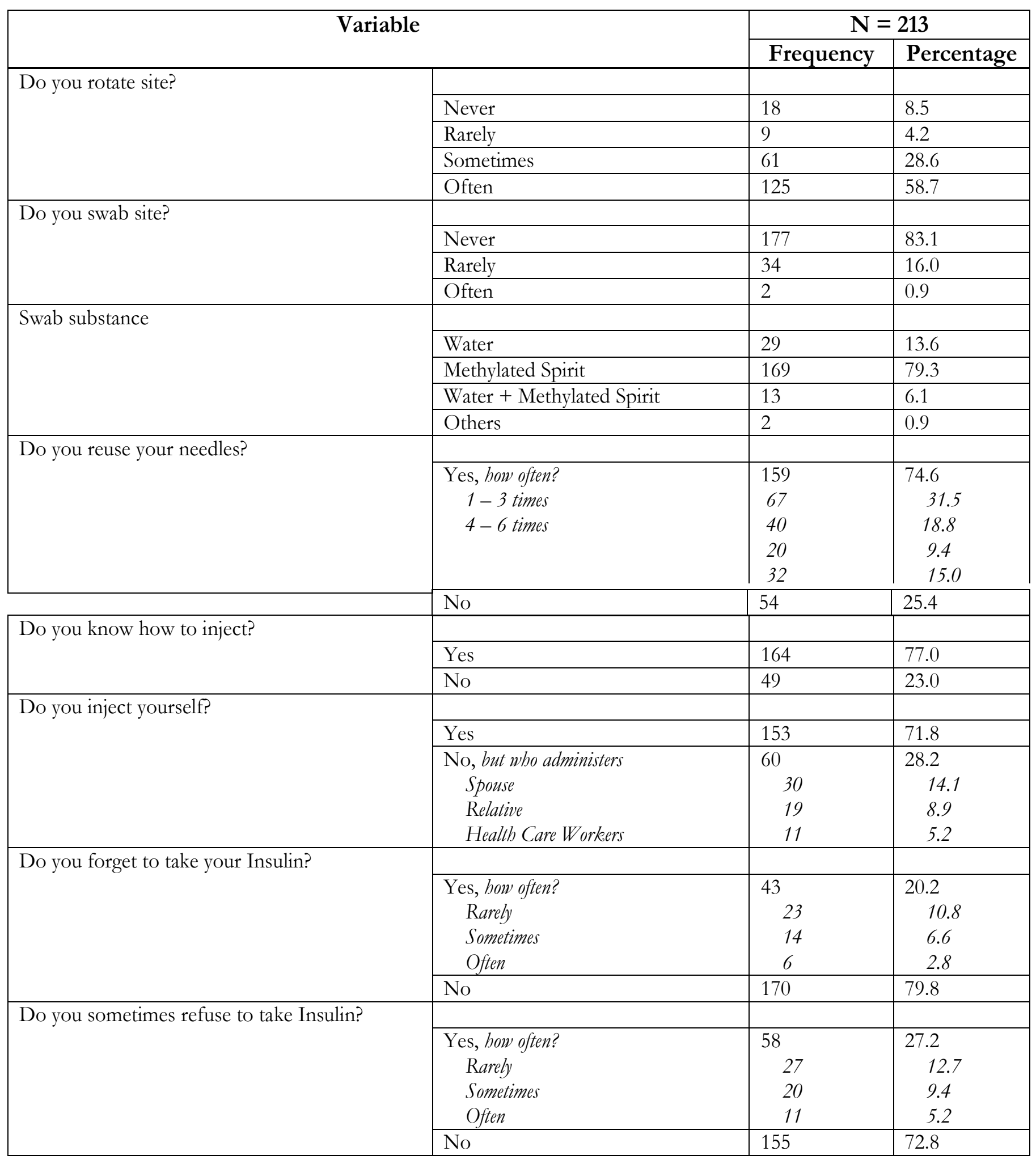




\section{Reasons forinsulin omission}

All of the 7 major reasons for insulin omission are as shown in Figure 2; the commonest cause of insulin omission which occurred in $42(20.2 \%)$ was insulin not available.

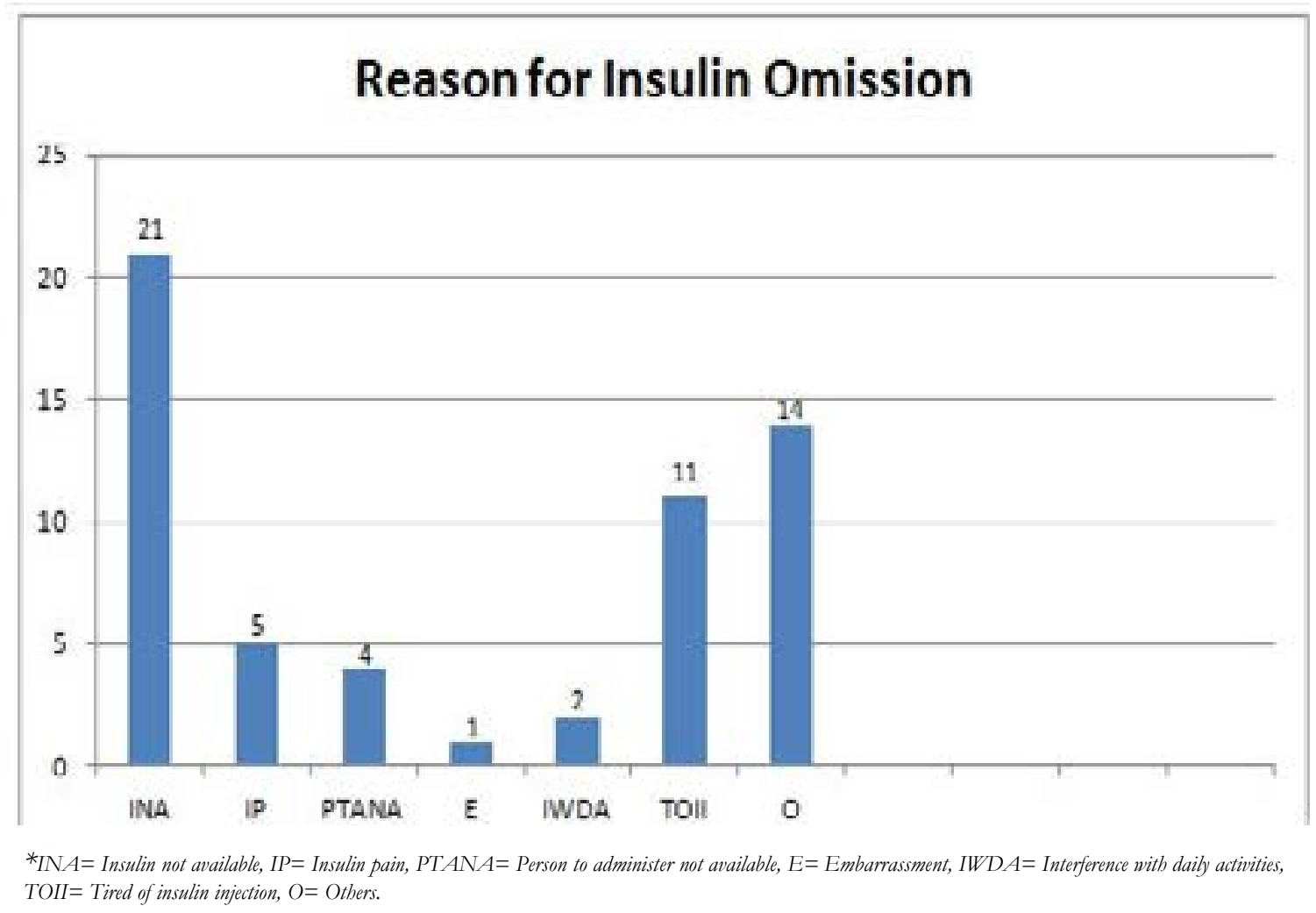

Figure 2: Reason for omitting insulin.

\section{Hypoglycaemia and self-monitoring of blood glu- cose (SMBG)}

While a total of $158(74.2 \%)$ of the study participants had glucometers, but 128 (69.4\%) do self-monitoring of blood glucose (SMBG). The number of participants who checked their blood glucose everyday was $64(30 \%)$ while 84 (39.4\%) checked their blood glucose 3-10 times/ months. Almost a third (31.9\%) of participants have had at least an episode of hypoglycaemia within the last 3 months but only $17(7.9 \%)$ had $\geq 3$ episodes of hypoglycaemia in the last 3 months. Of the 21 participants who had been managed in the hospital on account of hypoglycaemia within the last 3 months, 20/21 (95.2\%) had admission only 1-2 times (Table 4). 
Table 4: Pattern of Hypoglycaemia/SMBG.

\begin{tabular}{|c|c|c|c|}
\hline \multicolumn{2}{|l|}{ Variable } & \multicolumn{2}{|l|}{$\mathrm{N}=213$} \\
\hline \multirow{4}{*}{ Possess glucometers } & & Frequency & Percentage \\
\hline & & & \\
\hline & Yes & 158 & 74.2 \\
\hline & No & 55 & 25.8 \\
\hline \multirow[t]{6}{*}{ SMBG frequency } & & & \\
\hline & Never & 12 & 5.6 \\
\hline & Rarely $(1-2)$ & 53 & 24.9 \\
\hline & Sometimes $(3-5)$ & 45 & 21.1 \\
\hline & Often $(6-10)$ & 39 & 18.3 \\
\hline & Everyday & 64 & 30.0 \\
\hline \multicolumn{4}{|c|}{ Experience of hypoglycaemia } \\
\hline & Yes, how often? & 68 & 31.9 \\
\hline & Rarely (1 - 2) & 51 & 23.9 \\
\hline & Sometimes $(3-5)$ & 12 & 5.6 \\
\hline & Often $(6-10)$ & 5 & 2.3 \\
\hline & Everyday & 0 & 0.0 \\
\hline & No & 145 & 68.1 \\
\hline \multicolumn{4}{|c|}{ Hypoglycaemia admission } \\
\hline & Yes, bow many times? & 21 & 9.9 \\
\hline & $1-2$ times & 20 & 9.4 \\
\hline & $3-5$ times & 0 & 0.0 \\
\hline & $>5$ times & 1 & 0.5 \\
\hline & No & 192 & 90.1 \\
\hline
\end{tabular}

\section{Insulin injection sites examinations}

Figure 3 showed the distribution of adverse skin reactions noted at the insulin injection sites. The commonest skin lesion noted was hyperpigmentation found in $21.1 \%$ of participants and lipohypertrophy present in $13.2 \%$ of the participants.

\section{Inspection of Insulin Injection site}

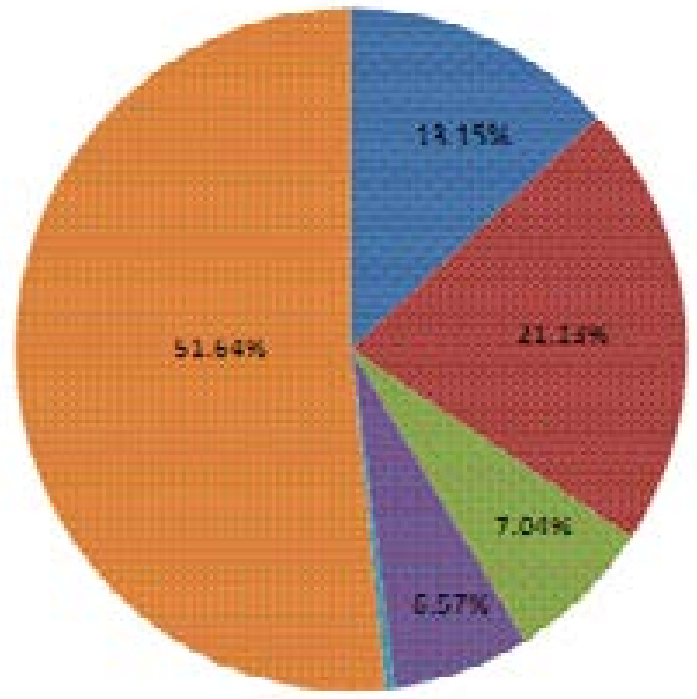

Hypertrophy

Hyperpigmentation

Wypopigmentation

IIkinrash

tipontrophy

Normal

Figure 3: Inspection of the insulin injection sites. 


\section{Insulin burden}

A substantial number of participants (40.4\%) said they planned their daily activities around their insulin injections and $(20.2 \%)$ reported that insulin injections interfered with their eating/exercise. Almost one-fifth (20.2\%) of the participants said that insulin injections had a negative effect on their social activities. A significant proportion of participants $(71.9 \%)$ reported moderate levels of non-satisfaction with the insulin pain. Ease of insulin used noted only in $(44.1 \%)$ of the study participants (Table 5).

\section{Table 5: Burden of insulin injection}

\begin{tabular}{|l|l|l|l|l|}
\hline \multirow{2}{*}{ Burden } & \multicolumn{1}{|c|}{ Not at all } & \multicolumn{1}{|c|}{ Little amount } & \multicolumn{1}{|c|}{ Moderate amount } & \multicolumn{1}{c|}{ Great deal } \\
\cline { 2 - 5 } & \multicolumn{1}{|c|}{$\mathbf{N}(\mathbf{\%})$} & $\mathbf{N}(\mathbf{\%})$ & \multicolumn{1}{|c|}{$\mathbf{N ~ ( \% )}$} \\
\hline Interference with eating/exercise & $170(79.8)$ & $30(14.1)$ & $12(5.6)$ & $1(0.5)$ \\
\hline Negative effect on social activities & $169(79.3)$ & $28(13.1)$ & $14(6.6)$ & $2(0.9)$ \\
\hline Daily activities around injection & $127(59.6)$ & $48(22.5)$ & $17(8.0)$ & $21(9.9)$ \\
\hline & Very satisfied & satisfied & Somewhat satisfied & Not at all satisfied \\
\hline Ease of Insulin used & & & & $10(4.7)$ \\
\hline Pain & $94(44.1)$ & $82(38.5)$ & $27(12.7)$ & $23(10.8)$ \\
\hline
\end{tabular}

\section{Discussion}

Despite the importance of adhering to prescribed insulin regimens, little is known about the degree to which patients are adhering. In this study, $69.0 \%$ of the participants practiced SMBG. The proportion of patients who performed SMBG in our study was slightly lower than $70-80 \%$ reported by workers in developed countries ${ }^{16,17}$ but significantly higher than $40 \%$ reported by Iwuala et $\mathrm{al}^{18}$ in Nigeria. Although the issue of cost as a possible barrier to SMBG amongst Nigerians with DM is already stated, because the expenses are mostly borne out-ofpocket ${ }^{19}$. However, diabetic patients on insulin are usually encouraged by their health care providers to monitor their blood glucose, hence the relatively high number of diabetics that owned glucometers and monitored their blood glucose in this study. The American Diabetes Association (ADA) has statutory recommendations for SMBG on use of glucometer in all diabetic patients on insulin ${ }^{20}$. Approximately $30 \%$ of our patients did not have access to glucometer, although they are on insulin. Other studies from developing countries like Kenya reported a lower utilization of glucometers and adherence ${ }^{21,22}$.
Insulin syringes were used by $55.4 \%$ of our participants, whereas $44.6 \%$ used insulin pen device. This finding is similar to the $45 \%$ of diabetic patients on insulin pen device in the USA, but higher than 33\% reported in Mexico $^{23}$ and $29 \%$ by Ogbera et $\mathrm{al}^{24}$ in Lagos. Our findings were different from that of the DiabCare India Study where $65.6 \%$ used pen device, $32.0 \%$ used syringes ${ }^{25}$. Also findings from multinational MOSA1C revealed that majority used pen device over syringes in countries like China (100\%), Germany (95\%), Russia (93\%) and Saudi Arabia $(63 \%)^{23}$. Data from a recent large worldwide survey indicated that insulin pen alone was used by $85.6 \%$ of patients, while $9.6 \%$ used a syringe device, $2.8 \%$ used both, and $1.4 \%$ used a pen and another device (usually insulin pumps ${ }^{26}$. Insulin syringes remain the commonly used delivery device due to its accessibility. Insulin pens which are more convenient to use, more accurate, take less time to teach patients and its needle less painful are at present not as readily available as insulin syringe to most patients with diabetes at the study centre. Also noted in this study, was the relatively low use of insulin analogues. In the study reported by Ogbera et $\mathrm{al}^{24}$ in 2012 , the percentage of insulin analogue use was $29 \%$ compared to 
$19.2 \%$ in this study. The reasons for the lower use of insulin analogue may be partly due to lower disposable income among our participants. Insulin analogues are more expensive than human insulin and also less accessible in our study centre.

This study showed that only $38.5 \%$ of the participants had adequate glycaemic control (FPG $<126 \mathrm{mg} / \mathrm{dl})$ and it is consistent with other studies ${ }^{27,28}$ who reported similar low glycaemia control. Glycated haemoglobin (HbA1C) which is considered as gold standard to assess levels of glycaemic control was not used among our participants; hence, the use of FPG levels (average of 3 most recent FPG tests) was used to assess and monitor glyceamic control. The ADA position statement with the standard of diabetic care recommend that a patient with good glycaemic control, at least $\mathrm{HbA} 1 \mathrm{C}$ test be done twice per year while in patients with poor glycaemic control, HbA1C test should be done 3-4 monthly ${ }^{20}$.

Also noted in this study is the high rate of insulin needle reuse $(74.6 \%)$ among our patients; $9.4 \%$ reused needle 7-10 times and 15.0\% reused insulin needle more than 10 times. In a study by Frid et $\mathrm{al}^{26}$, they found needle reuse in approximately half of the patients worldwide, almost a third using the same needle up to 6 times. Also, Baruah et $\mathrm{al}^{29}$ found $72.2 \%$ of their patients reused insulin needle and $98.9 \%$ in the South Indian Study ${ }^{30}$. In contrast, more than $80 \%$ of patients avoid needle reuse in developed nations like Italy ${ }^{31}$. Recent guidelines have strongly discouraged needle reuse although optimal cutoff for maximum number of injection reuse has not been $\operatorname{set}^{32}$. Major reasons thought to be responsible for the high rate of needle reuse in our study are cost and inadequate education of the patients by the health care providers. As previously reported by Olamoyegun et $\mathrm{al}^{14}$, even health care practitioners (HCPs) had poor knowledge of insulin use, hence may not be able to give patients adequate assistance, when they raise the issue with them.

In the present study, the storage condition of insulin was appropriate as majority of participants stored their insulin in the refrigerator. Vials of insulin not in use should be refrigerated. Excessive temperatures $\left(<2^{\circ} \mathrm{C}\right.$ or $\left.28^{\circ} \mathrm{C}\right)$ and excessive shaking should be avoided to prevent loss of potency, clumping, frosting and precipitation. Insulin in use may be kept at room temperature, behind local water pot and in cool places away from direct sunlight in the absence of refrigerator so as to maintain potency.

Adherence to anti-diabetic agents including insulin is one of the important determinants of optimal glycaemic control among diabetics. Insulin adherence rate in this study of $79.8 \%$ is comparable to $77 \%$ reported by Ogbera et $\mathrm{al}^{24}$ in a previous study in Nigeria. Majority of our patients practiced self-insulin injection, hence positively affected their insulin adherence. In contrast to other studies that found evidence of poor adherence to insulin therapy among patients with diabetes ${ }^{33}$ they noted that only $28 \%$ of their patients were adherent to insulin therapy.

We noted that some patients deliberately omitted or forgot to inject the insulin they were meant to take. In this study, pain, ease of insulin use and embarrassment associated with insulin injection resulted in insulin omission. This is similar to findings by Peyrot et al who reported pain and embarrassment as some of the reason for insulin omission among both type 1 and type 2 diabetic patients ${ }^{33}$. Our study also suggests that insulin omission is affected by the perceived burden of insulin therapy including having to plan one's life around insulin injections and feeling that the insulin regimens interfere with activities of daily living such as social activities. Measures to reduce this perceived burden of insulin injections may require repeated health education by health care providers emphasizing adherence. Also, a finding in this study suggests that insulin omission may be affected by previous or perceived experience that injecting insulin is painful and uncomfortable. However, adopting alternative ways to deliver insulin like insulin pens, finer gauge needles are some of the ways to reduce pain, reduce inconvenience and ameliorate embarrassment. Measures adopted to address pain and embarrassment due to insulin injection may also help to lessen the emotional burden of injections, thereby improving psychological well-being and adherence.

Limitations of the study include the fact that measure of insulin adherence was based on patients' admittance rather than objective means like pharmacy records or frequency of drugs refill. Also, long-term glycaemic control was assessed with average of three most recent FPG rather than with glycated haemoglobin which is the usual measure of long-term glycaemic control ${ }^{25}$. 


\section{Authors' contributions}

OMA \& AAT, were involved in the conception, and design of this study. OMA analyzed the data, drafted the manuscript. All authors were involved in revising the manuscript critically for intellectual content and provided a final approval of the version to be published.

\section{Conflict of interest}

Nil.

\section{References}

1. Ogurtsova K, da Rocha Fernandes JD, Huang Y, Linnenkamp U, Guariguata L, Cho NH, Cavan D, Shaw JE, Makaroff LE. IDF Diabetes Atlas: Global estimates for the prevalence of diabetes for 2015 and 2040. Diabetes Res Clin Pract. 2017 Jun;128:40-50. doi: 10.1016/j.diabres.2017.03.024. Epub 2017 Mar 31. PubMed.

2. Ejim EC, Okafor CI, Emehel A, Mbah AU, Onyia U, Egwuonwu T, et al. Prevalence of cardiovascular risk factors in the middle-aged and elderly population of a Nigerian rural community. J Trop Med. 2011;2011:308687.

3. Osuji CU, Nzerem BA, Dioka CE. Prevalence of diabetes mellitus in a group of women attending "August meeting" at Naze South East Nigeria. J Diabetes Mellitus. 2012;2:321-6. PubMed.

4. Ige OK, Owoaje ET, Adebiyi OA. Non communicable disease and risky behaviour in an urban university community Nigeria. Afr Health Sci. 2013;13:62-7. PubMed.

5. Ekpenyong CE, Akpan UP, Ibu JO. Gender and age specific prevalence and associated risk factors of type 2 diabetes mellitus in Uyo metropolis, South Eastern Nigeria. Diabetol Croat. 2012;41:17-28. PubMed.

6. Oluyombo R, Olamoyegun MA, Olaifa O, Iwuala SO, Babatunde OA. Cardiovascular risk factors in semi-urban communities in southwest Nigeria: Patterns and prevalence. J Epidemiol Glob Health. 2015; 5(2):167-74. doi: 10.1016/j.jegh.2014.07.002. PMID: 25922326. PubMed 7. Fadare J, Olamoyegun MA, Gbadegesin BA. Medication adherence and direct treatment cost among diabetes patients attending a tertiary health care facility in Ogbomosho, Nigeria. Malawi Med J. 2015 Jun; 27 (2): 65-72.

8. Ogbera A, Adeyemi-Doro A. Emotional distress is associated with poor self-care in type 2 diabetes mellitus. J Diabetes. 2011 Dec;3(4):348-52. doi: 10.1111/j.17530407.2011.00156.x.

9. Chinenye S, Uloko AE, Ogbera AO, Ofoegbu EN, Fasanmade OA, Fasanmade AA, Ogbu OO. Profile of
Nigerians with Diabetes Mellitus-Diabcare Nigerian Study group (2008): Results of a multicenter study. Indian J Endocrinol Metab. 2012 Jul-Aug;16(4):558-564.

10. Ahmad S, Osman MT, Jaffar A, Rashed MRA, Hassan MR, Supian ZA. Education of correct insulin injection technique amongst diabetic patients: outcome study from Malaysia. J Med Res \& Health Sc. 2016; 5(6):198-205. PubMed.

11. The Diabetes Control and Complications Trial Research Group. The Effect of Intensive Treatment of Diabetes on the Development and Progression of LongTerm Complications in Insulin-Dependent Diabetes Mellitus. N Engl J Med. 1993; 329:977-986. PubMed. DOI: 10.1056/NEJM199309303291401

12. UK Prospective Diabetes Study (UKPDS) Group. Intensive blood glucose control with sulphonylureas or insulin compared with conventional treatment and risk of complications in patients with type 2 diabetes. Lancet. 1998;352(9131):837-53. PubMed.

13. Shaefer Jr CF. Patients and physician barriers to instituting insulin therapy: a case-based based overview. Insulin. 2007;2: S41-S46.

14. Olamoyegun MA, Iwuala SO, Olamoyegun KD, Olaniregun $\mathrm{OO}$, Kolawole BA. Insulin-related knowledge of health care professionals (HCPs) in a Nigerian tertiary health institution. International Journal of Diabetes in Developing Countries. 2015;35(2):84-89.

15. Ogbera AO, Fasanmade OA, Chinenye S, Akinlade A. Characterization of lipid parameters in diabetes mellitus - a Nigerian report. Int Arch Med. 2009;2(1):19. PubMed. doi: 10.1186/1755-7682-2-19

16. Davis WA, Bruce DG, Davis TM. Is self-monitoring of blood glucose appropriate for all type 2 diabetic patients? The Fremantle Diabetes Study. Diabetes Care. 2006;29:1764-70. PubMed.

17. Khunti K, Davies MJ, Kalra S. Self-titration of insulin in the management of people with type 2 diabetes: A practical solution to improve management in primary care. Diabetes Obes Metab. 2013;15:690-700. PubMed.

18. Iwuala SO, Olamoyegun MA, Sabir AA, Fasanmade OA. The relationship between self-monitoring of blood glucose and glycaemic controlamong patients attending an urban diabetes clinic in Nigeria. Ann Afr Med. 2015;14:182-7. PubMed.

19. Odeyemi IA, Nixon J. Assessing equity in health care through the national health insurance schemes of Nigeria and Ghana: A review-based comparative analysis. Int J Equity Health. 2013;12:9.

African Health Sciences Vol 18 Issue 4, December, 2018 
20. American Diabetes Association. Standards of medical care in diabetes-2016. Diabetes Care. 2016;39(suppl 1):S1-S106.

21. Wambui Charity K, Kumar AM, Hinderaker SG, Chinnakali P, Pastakia SD, Kamano J. Do diabetes mellitus patients adhere to self-monitoring of blood glucose (SMBG) and is this associated with glycemic control? Experiences from a SMBG program in Western Kenya. Diabetes Res Clin Pract. 2016;112:37-43.

22. Ji L, Su Q, Feng B, Shan Z, Hu R, Xing X, et al. Glycemic control and self-monitoring of blood glucose in Chinese patients with type 2 diabetes on insulin: Baseline results from the COMPASS study. Diabetes Res Clin Pract. 2016;112:82-7.

23. Polinski JM, Kim SC, Jiang D, Hassoun A, Shrank $\mathrm{WH}, \mathrm{Cos} \mathrm{X}$, et al. Geographic patterns in patient demographics and insulin use in 18 countries, a global perspective from the multinational observational study assessing insulin use: Understanding the challenges associated with progression of therapy (MOSAIc). BMC Endocr Disord. 2015;15:46.

24. Ogbera AO, Kuku SF. Insulin use, prescription patterns, regimens and costs.-a narrative from a developing country. Diabetol Metab Syndr. 2012; 4: 50. doi: 10.1186/1758-5996-4-50

25. Mohan V, Shah SN, Joshi SR, Seshiah V, Sahay BK, Banerjee $\mathrm{S}$, et al. Current status of management, control, complications and psychosocial aspects of patients with diabetes in India: Results from the DiabCare India 2011 Study. Indian J Endocrinol Metab. 2014;18:370-8.

26. Frid AH, Hirsch LJ, Menchior AR, Morel DR, Strauss KW. Worldwide injection technique questionnaire study:
Population parameters and injection practices. Mayo Clin Proc. 2016;91:1212-23. PubMed.

27. Adewolu O F. Glycaemic Control in Patients with Type 2 Diabetes Mellitus in a Secondary and Tertiary Health Center in Oredo and Egor Local Government Areas in Benin City, South-South Nigeria. International Journal of TROPICAL DISEASE \& Health. 2014 Jun; 4(6): 621-633.

28. Musege EM, Manankov A, Mudeda B, Michelo C. Glycaemic control in diabetic patients in Zambia. The Pan African Medical Journal. 2014;19:354. doi:10.11604/ pamj.2014.19.354.5264. PubMed.

29. Baruah MP, Kalra S, Bose S, Deka J. An audit of insulin usage and insulin injection practices in a large Indian cohort. Indian J Endocr Metab. 2017;21:443-52

30. Patil M, Sahoo J, Kamalanathan S, Selviambigapathy J, Balachandran K, Kumar R, et al. Assessment of insulin injection techniques among diabetes patients in a tertiary care centre. Diabetes Metab Syndr. 2016:pii: S1871402130211-9

31. Grassi G, Scuntero P, Trepiccioni R, Marubbi F, Strauss K. Optimizing insulin injection technique and its effect on blood glucose control. J Clin Transl Endocrinol. 2014;1:145-50.

32. Kalra S, Balhara YP, Baruah MP, Chadha M, Chandalia HB, Chowdhury S, et al. Forum for injection techniques, India: The first Indian recommendations for best practice in insulin injection technique. Indian J Endocrinol Metab. 2012;16:876-85.

33. Peyrot M, Rubin RR, Kruger DF, Travis LB. Correlates of insulin injection omission. Diabetes Care. 2010;33(2): 240-245. PubMed. https://doi.org/10.2337/dc09-1348 